\title{
The road to competitive generic drug prices in Canada
}

\author{
Michael R. Law PhD, Jillian Kratzer MSc
}

$\mathrm{T}$ The price of generic drugs has generated much debate over the past several years. The latest development came at a meeting of all Canadian premiers, who called for a national program of bulk purchasing to achieve lower generic drug prices. 1 Although on the surface this appears to be a simple change, in reality it is a fundamental shift in how Canada prices its generic medicines.

Generic prices are becoming increasingly important for both public and private drug plans. Patent expirations on blockbuster drugs will result in about one-third of total 2009 drug expenditures having "gone generic" by $2014 .{ }^{2}$ As a consequence, the use of generic drugs in Canada is poised to increase. $^{3}$ At this juncture, it is worth reflecting on past attempts to encourage more competitive generic pricing, because they offer valuable insight as to how the provinces should proceed.

\section{The past: compulsory licensing followed by regulated price caps}

In the past, Canada focused less on the specific price of generic drugs than on using them to regulate brand prices. ${ }^{4}$ Prior to 1992 , during the era of compulsory licensing, generic firms could manufacture versions of on-patent drugs early in exchange for a $4 \%$ royalty paid to the brand manufacturer. ${ }^{5}$ Typically, generic versions of patented drugs would come onto the market at $75 \%$ of the brand price after 5-7 years, meaning that Canadians got an "early" discount on many medicines. ${ }^{6}$ With multiple generic manufacturers, prices of generic drugs dropped on average to $35 \%$ of the equivalent brand-name price. ${ }^{4}$

In 1992, compulsory licensing was eliminated, spelling the end of Canada's use of generic competition to control brand prices. The next year, Ontario introduced the "70/90 rule," which set price ceilings for the first generic entrant at $70 \%$ of the brand price and all subsequent entrants at $90 \%$ of this price. ${ }^{7}$ The evidence suggests this rule had an ironic impact: the prices for many generic drugs rose to congregate at the cap. ${ }^{7}$ By the mid-2000s, evidence indicated that these prices were much higher than in other industrialized countries. ${ }^{89}$
Nevertheless, this pricing method - using an arbitrary percentage of the equivalent brandname price - had become the standard across Canada. This left a wide margin between the prices drug plans would reimburse and the price at which generic manufacturers were actually willing to provide their products. As a result, generic firms started competing for pharmacy shelf space by paying "rebates" to pharmacies in exchange for stocking their products. ${ }^{10} \mathrm{By}$ the mid-2000s, these "rebates" were a major source of pharmacy revenue: audits pegged them at $\$ 800$ million annually in Ontario alone. ${ }^{11}$

\section{The present: blunt moves in percentages}

These pricing differences were not lost on regulatory agencies and policy-makers: the past 6 years have witnessed a high-profile investigation from the Competition Bureau and changes to generic prices in nearly every province. ${ }^{12}$ Although Ontario now prices at a nationwide low of $25 \%$ of the originator brand (and 20\% for the top 10 drugs), other provinces have independently moved to $25 \%, 35 \%$ or have remained unchanged (usually at around 65\%). The result: across Canada there is huge price variation.

The problem is that percentage-based caps will never get Canadians the right price. There is no reason to believe that the brand-name price should bear any resemblance to the cost of developing and manufacturing a generic version. Percentage-based prices result in 1 of 2 outcomes: The first is that drug plans systematically
Competing interests: None declared.

This article has been peer reviewed.

Correspondence to: Michael R. Law, mlaw@chspr.ubc.ca

CMAJ 2013. DOI:10.1503 /cmaj.121367

\section{- KeY POINTS}

- Despite recent reforms, Canada continues to have higher generic prescription drug prices than other comparable countries.

- In June 2012, the premiers made a joint commitment to use competitive bidding to lower the prices of generic drugs.

- If successful, this initiative would result in substantial drug plan savings.

- Past Canadian attempts at introducing competitive bidding suggest this initiative should include as many drugs and provinces as possible.

- The premiers should introduce universal coverage for some generic drugs; such a move would improve health and still be cost saving. 
overpay for generic drugs that 1 or more manufacturers would have been willing to sell for less.

The second possible outcome is that the percentage-based price is too low, and provincial governments thus have to grant exemptions to the pricing rule. For example, when British Columbia reduced prices to $35 \%$, the province granted over 600 exemptions for specific products, dramatically reducing their expected savings. This creates a heavy burden on regulators. It is also unlikely that this process drives prices down to what the most efficient manufacturers would sell at. Thus, it is highly likely that regulatory exemptions still result in inflated prices.

\section{The future: Competitive bidding?}

Our goal in pricing generic drugs should be to provide a reliable supply of high-quality medicines at the best possible cost. The approach advocated by the premiers of bulk purchasing through competitive bidding is simple — award volume-based contracts for the supply of a particular generic ingredient in return for better prices. Canadian hospitals and other countries have used similar purchasing strategies for many years. ${ }^{8,10}$

The potential savings to Canadians are substantial. Even though Ontario has Canada's lowest prices, 9 of 10 generic drugs are more expensive in this province than in other public drug plans that use competitive bidding. ${ }^{13}$ Figure 1 shows the degree of price discrepancies for 5 widely used generic products between 2 Canadian provinces and 2 international public insurance programs that use competitive bidding contracts. Achieving international prices for the top 100 generic drugs would save the people of Ontario nearly a quarter billion dollars every year. ${ }^{13}$

However, Canadian attempts at competitive bidding have been tried by at least 3 public drug plans in Canada, with disappointing results. It appears that the success of this new endeavour by the provinces will hinge on how it is designed and implemented. Each past attempt has taught us the following important lessons for seeking more competitive prices.

\section{Make the prize large}

Saskatchewan currently uses so-called "standing offer contracts" with particular manufacturers for supplying generic ingredients to their public drug plan. Although contracts have been awarded for some generic drugs, participation by generic firms has been limited. ${ }^{15}$ This most likely results from "most favoured nation" clauses (such as Quebec's) that oblige manufacturers to provide

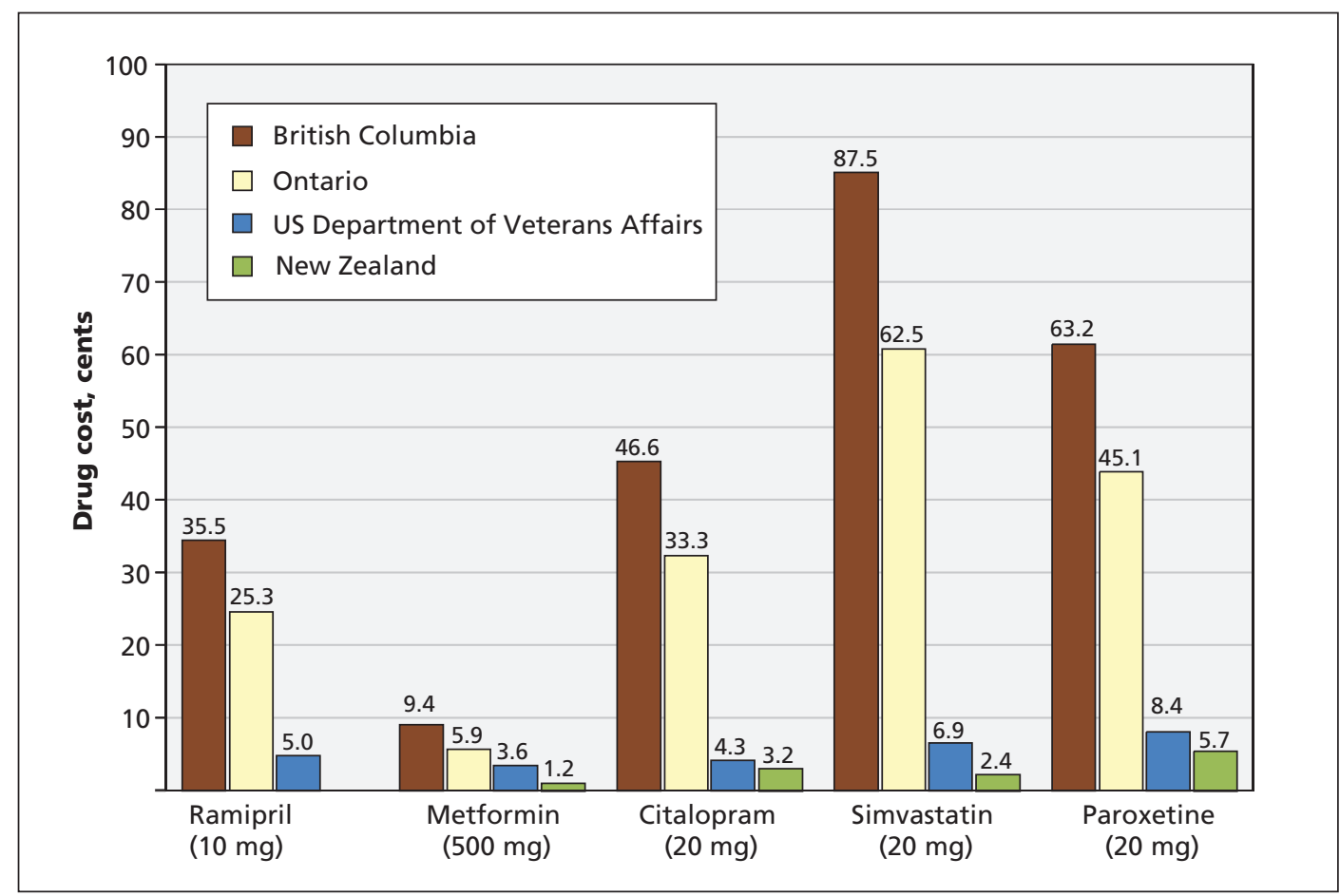

Figure 1: The comparative price per unit for select generic drugs between 2 Canadian provinces (British Columbia and Ontario, at $35 \%$ and $25 \%$ of the originator brand, respectively) and 2 public drug programs that use bulk purchasing (the United States Department of Veterans Affairs and New Zealand's Pharmaceutical Management Agency) in 2011. ${ }^{13,14}$ These drugs were among the top 5 generic drugs in terms of potential savings in Ontario in $2009 .{ }^{13}$ British Columbia prices were adjusted to reflect the inclusion of markups in the provincial formulary. Pricing data for New Zealand were not available for ramipril, because it is not included in the public formulary. Foreign prices were converted to Canadian currency using 2011 average annual exchange rates. 
Saskatchewan's public drug plan the best price offered elsewhere. ${ }^{15}$ The lesson from this experience is that the prize must be suitably large to induce generic manufacturers to participate, because they would need to offset their losses from lower prices in Quebec. Thus, efforts should be made to include as many provinces as possible and as many widely used drugs as possible in the purchasing arrangement. For this reason, the provinces should seriously consider expanding the number of drugs beyond the 3 to 5 currently proposed.'

\section{Ensure there is a competition and transparency}

The second example comes from British Columbia, where in 2007 the provincial Pharmacare program tendered the supply of the antipsychotic olanzapine. ${ }^{16} \mathrm{At}$ the time, there were only 2 manufacturers - the brand manufacturer Eli Lilly and the generic manufacturer Novopharm. The supply contract was ultimately awarded to Eli Lilly, subsequent to which Novopharm launched a lawsuit claiming the province had conspired to harm their business in British Columbia. The province ultimately won, but this experience makes it clear that any competitive process should be conducted under clear and transparent rules. Further, this experience and past research both indicate that competitive bidding works more effectively when there are many manufacturers. ${ }^{17}$

\section{Allow brand and international manufacturers to participate, and eliminate rebates}

In 2008, the public drug plan in Ontario announced plans to tender the supply of 4 widely used generic drugs. ${ }^{18}$ Ultimately just one of these tenders was successfully executed - a contract to supply enalapril maleate was awarded to the brand-name manufacturer. In both British Columbia and Ontario to date, generic firms have not won tendering agreements. Further, Ontario allowed international manufacturers to bid, but required that they fulfill Canadian regulatory requirements in a very short period. Together, these factors suggest that to increase competition, brand-name manufacturers should be welcome to participate, and sufficient time should be permitted for international bidders to obtain Canadian regulatory approval.

The most likely factor that impeded genuine participation by generic manufacturers was the potential that pharmacies would retaliate against them - because of lost rebate income - by decreasing their purchases of other products from winning firms. One potential solution would be to make pharmacies indifferent to which firm wins competitive contracts. Banning rebates on all generic purchases (not just the drugs for which competitive bidding is initiated) would accomplish this by breaking the link between generic prices and pharmacy revenue.

\section{Possible arguments against bulk purchasing}

The opponents of using more competitive procurement methods will point out that Canada's high generic prices indirectly support at least 2 related activities. These need to be considered as changes are made. First, pharmacies should be compensated for dispensing and counselling services at a level that maintains their accessibility. However, given that Canada sustains $40 \%$ more pharmacies per capita than the United States, concerns that pharmacy consolidation would affect access to pharmacies are likely overstated. ${ }^{19}$

Second, generic firms should engage in potentially costly patent litigation that can result in generic drugs coming to market earlier. ${ }^{16}$ Although some may consider it reasonable to reward the firm that challenges a recent patent, there is no reason to inflate the cost of all generic drugs - even old ones that have been off patent for decades - to do so. A different mechanism, such as a period of exclusivity (as practised in the United States), or the payment of royalties by competitors to the manufacturers that challenge relevant patents would be much more targeted. ${ }^{16}$

Critics have also argued that tendering may result in drug shortages. ${ }^{20}$ For example, much was made of the sole-source contracts used by hospitals in Canada to procure particular injection therapies for surgical procedures..$^{20}$ This speaks to the need to choose the products that are bulk purchased wisely. To start, the bulk purchasing initiative should focus on commonly used solid oral drugs that are produced by many manufacturers. In the longer-term, it seems unlikely that highly globalized generic manufacturers would abandon such drugs because they did not win a contract in the comparatively small Canadian market. However, this should be monitored moving forward.

International best practices should also be used in contracting to safeguard the stability of supply, such as clauses requiring suppliers to pay for required backup supplies. ${ }^{21}$ Another option would be to award multiple supply contracts. However, such provisions come at a cost. ${ }^{22}$ For example, New Zealand reports that dual-sourcing medicines leads to $17 \%$ higher prices than single sourcing. ${ }^{23}$ Having a reliable supply of medicines is important. However, additional security comes at a cost that must be weighed against the other health care services that those funds could purchase. 


\section{An opportunity for better drug coverage}

Regardless of which drugs are chosen, the opposition from pharmacies and generic manufacturers will likely be very strong. Moving forward with competitive purchasing for generic drugs will require political will and strong public support. Although the prospect of public-sector savings may result in some public support, our generic prices are high enough that expanding medicare coverage becomes a viable option.

In fact, Canadian prices are still high enough that a universal coverage program for specific generic drugs could be instituted where full public coverage is introduced using the cost savings. ${ }^{24}$ Based on the prices in other countries, there are several drugs that would fulfill these criteria. ${ }^{13}$ Such a cost-saving and health-promoting program would aid the many Canadians who cannot afford their prescription medicines and negate the claims from stakeholders that bulk purchasing is not in the public interest. ${ }^{25}$

\section{Conclusion}

Compared with people in other countries, Canadians pay high prices for generic drugs. The joint commitment from Canada's premiers to use coordinated bulk purchasing to lower these prices is important, and, moving forward, governments should learn from past attempts at obtaining more competitive prices. It should be clear from the outset that the provinces intend this to be the future of generic pricing, and political support should be secured by offering Canadians universal public coverage for this first round of medications. By changing the way Canada procures medicines, this joint commitment is a true opportunity to both reduce drug expenditures and improve access to health care.

\section{References}

1. Health Care Innovation Working Group. From innovation to action: the first report of the Health Care Innovation Working Group. Ottawa (ON): The Council of the Federation; 2012. Available: www.councilofthefederation.ca/pdfs/Health\%20Innovation $\% 20$ Report-E-WEB.pdf (accessed 2012 July 26).

2. Drivers of prescription drug spending in Canada. Ottawa $(\mathrm{ON})$ : Canadian Institute for Health Information; 2012. Available: www .cihi.ca/CIHI-ext-portal/pdf/internet/DRUG_SPEND_DRIVERS _EN (accessed 2012 July 24)

3. The role of the generic pharmaceutical industry in Canadian health - 2011. Toronto (ON): Canadian Generic Pharmaceutical Association; 2012. Available: www.canadiangenerics .ca/en/advocacy/docs/The\%20Role\% 20 of $\% 20$ the $\% 20$ Generic $\%$ 20Pharmaceutical $\% 20$ Industry $\% 20$ in $\% 20$ Canadian $\% 20 \mathrm{Health} \%$ 20Care_2011.pdf (accessed 2012 July 23).

4. Lexchin J. Pharmaceuticals, patents, and politics: Canada and Bill C-22. Int J Health Serv 1993;23:147-60.

5. Smith M. Patent protection for pharmaceutical products (BP354e). Ottawa (ON): Library of Parliament/Parliamentary Research Branch; 1993. Available: http://publications.gc.ca
/Collection-R/LoPBdP/BP/bp354-e.htm (accessed 2012 July 17).

6. Lexchin J. Effect of generic drug competition on the price of prescription drugs in Ontario. CMAJ 1993;148:35-8.

7. Anis AH, Guh DP, Woolcott J. Lowering generic drug prices: less regulation equals more competition. Med Care 2003;41:135-41.

8. Morgan S, Hanley G, Mcmahon M, et al. Influencing drug prices through formulary-based policies: lessons from New Zealand. Healthc Policy 2007;3:e121-40.

9. Generic drugs in Canada: international price comparisons and potential cost savings. Ottawa (ON): Patented Medicine Prices Review Board; 2011. Available: www.pmprb-cepmb.gc.ca /CMFiles/Publications/Analytical\%20Studies/NPDUIS-Generic Drugs-IPCs-e-sept30.pdf (accessed 2012 July 15).

10. Generic Drug Sector Study. Ottawa $(\mathrm{ON})$ : Competition Bureau; 2007. Available: http://competitionbureau.gc.ca/eic/site/cb-bc .nsf/eng/02495.html (accessed 2012 July 15).

11. Lewis S. Ontario generic drug wars, part 1: how it all began. Toronto (ON): Longwoods Publishing Corporation; 2010. Available: www.longwoods.com/content/21910 (accessed 2012 July 18).

12. Benefiting from generic drug competition in Canada: the way forward. Ottawa (ON): Competition Bureau Canada; 2008. Available: http://competitionbureau.gc.ca/eic/site/cb-bc.nsf/eng /02753.html (accessed 2012 July 15).

13. Law MR. Money left on the table: generic drug pricing in Canada [working paper]. Vancouver (BC): UBC Centre for Health Services and Policy Research; 2012. Available: www.chspr.ubc.ca /pubs/working-papers/money-left-table-generic-drug-prices-canada (accessed 2012 Sept. 23).

14. PharmaCare formulary search. Vancouver (BC): British Columbia Ministry of Health; 2012. Available: www.health.gov.bc.ca/pharma care/benefitslookup/faces/Search.jsp (accessed 2012 Oct. 10).

15. Silversides A. Provincial experiments aim to lower public drug plan costs. CMAJ 2009;181:E80-2.

16. Hollis A. Generic drug pricing and procurement: a policy for Alberta. Calgary (AB): University of Calgary, School of Policy Studies; 2009. Available: http://policyschool.ucalgary.ca/files /publicpolicy/Hollis\%20ONLINE\%20\%28Feb\%2009\%29.pdf (accessed 2012 July 15)

17. Reiffen D, Ward MR. Generic drug industry dynamics. Review of Economics and Statistics 2005;87:37-49.

18. Ontario public drug programs competitive agreements: briefing for stakeholders. Toronto (ON): Ontario Ministry of Health; 2008. Available: www.health.gov.on.ca/english/providers/program/drugs /opdp_eo/notices/stakeholder_briefing.pdf (accessed 2012 July 11).

19. Law MR, Dijkstra A, Douillard J, et al. Geographic accessibility of community pharmacies in Ontario. Healthc Policy 2011;6:36-46.

20. Standing Committee on Health. Drug supply in Canada: a multi-stakeholder responsibility. Ottawa $(\mathrm{ON})$ : Canadian House of Commons; 2012.

21. Managing medicine supply. Wellington (NZ): New Zealand Pharmaceutical Management Agency; 2011. Available: www.pharmac .govt.nz/2011/09/16/07MANAGING_SUPPLY.pdf (accessed 2012 Apr. 17).

22. Gagnon M-A. Drug shortages: searching for a cure. Healthc Policy 2012;7:10-7.

23. Annual review 2009. Wellington (NZ): Pharmaceutical Management Agency; 2009. Available: www.pharmac.govt.nz/2009/10 /28/Annual\%20Report\%20-\%20year\%20ended $\% 2030 \% 20 J u n e \%$ 202009.pdf (accessed 2012 Aug. 12).

24. Law MR, Morgan SG. Purchasing prescription drugs in Canada: hang together or hang separately. Healthc Policy 2011;6:22-6.

25. Law MR, Cheng L, Dhalla IA, et al. The effect of cost on adherence to prescription medications in Canada. CMAJ 2012;184:297-302.

Affiliation: Centre for Health Services and Policy Research, School of Population and Public Health, Faculty of Medicine, The University of British Columbia, Vancouver, BC.

Contributors: Michael Law and Jillian Kratzer conceived this article and its design. Michael Law acquired, analyzed and interpreted the data, and wrote the first draft of the manuscript. Jillian Kratzer interpreted the data and revised the manuscript for important intellectual content. Both authors approved the final version submitted for publication.

Acknowledgements: This work was supported by an operating grant from the Canadian Institutes of Health Research (MOP-221233). Michael Law receives salary support through a New Investigator Award from the Canadian Institutes of Health Research and a Career Investigator Award from the Michael Smith Foundation for Health Research. 